\title{
Financing and the Protection of Innovators*
}

\author{
Gerard Llobet \\ $C E M F I$ \\ Javier Suarez \\ CEMFI, CEPR, and ECGI
}

February 2005

\begin{abstract}
The protection that innovators obtain through intellectual property rights crucially depends on their incentives and ability to litigate infringers. Taking patents as a notable example, we study how the financing of legal costs can alter the incentives to litigate in defense of a patent and, thus, the prospects of infringement and the effective protection of the innovator. We compare the resort to a financier once the infringement has occurred (ex-post financing) with patent litigation insurance (PLI) as well as other ex-ante arrangements based on leverage. We show that the ex-ante arrangements can be designed (for instance, in the case of PLI, by including an appropriate deductible) so as to implement the innovator's second-best outcome: a situation in which patent predation is deterred without inducing excessive litigation.
\end{abstract}

JEL Codes: G32, O34, 052.

Keywords: financial strategy, intellectual property, litigation, predation.

*We thank Andres Almazan, Vicenzo Denicolo, Dima Leshchinskii, David Perez-Castrillo, Rafael Repullo, Ibolya Schindele, the participants at the 6th Bundesbank Spring Conference on Financing Innovation, the Second RICAFE Conference, the XX Jornadas de Economía Industrial, and the XXIX Simposio de Análisis Económico, as well as the seminar audience at CEMFI and Tilburg for their comments. Financial support from European Commission grant HPSE-CT-2002-00140 is gratefully acknowledged. Address for correspondence: CEMFI, Casado del Alisal 5, 28014 Madrid, Spain. Tel: +34-914290551. Fax: +34-914291056. Email: llobet@cemfi.es, suarez@cemfi.es. 


\section{Introduction}

Economic growth depends in large part on innovation. Laws recognizing intellectual property rights such as patents, trademarks, copyrights, and even trade secrecy are intended to reward innovators by means of protecting them from competition. However, the effective protection granted by those rights crucially depends on the incentives and ability of the innovators for litigating infringers. This paper studies the interactions between the financial arrangements made by innovators in order to pay for the legal defense of their intellectual property and the effective protection that they obtain. For concreteness, we focus on the notable example of patents, which are both the centerpiece of innovation policy and a common object of outrageously expensive legal disputes..$^{1}$

In fact, the importance of legal costs - with a median of about two million dollars per side $\sqrt{2}^{2}$ as well as the injunctions and damages (or the licensing fees agreed in the context of pre-trial settlement) often makes patent litigation a "bet-the-business" gamble for one or both sides in the dispute. Given the size of the legal expenses, lawyers are reluctant to work on these cases on a contingent-fee basis. Innovators which arrive at the litigation stage without internal funds (or another previously arranged source of finance) must resort to financiers such as banks and venture capitalists or to more specialized, litigation investment firms..$^{3}$ Of course, innovators can make arrangements for the legal defense of their patents before the risk of infringe-

\footnotetext{
${ }^{1}$ Based on US data for the period 1978-1995, Lanjouw and Schankerman (2004) estimate an average filing rate of 19 suits per thousand patents. This measure of litigation risk over the patent's life-span exhibits large variation across industries and patentee classes. Litigation risk is strongly decreasing in the size of the patentee's portfolio of patents and, for patents held by individuals and unlisted corporations, it is found to be 3-4 times higher than for those held by listed corporations.

${ }^{2}$ According to the Economic Survey conducted by American Intellectual Property Law Association, the median cost of a patent case was around 1.5 million dollars in 2001 and around 2 million in 2003. A report from CJA Consultants (2003) provides estimates for Europe in the range of 1.5 to 2 million euro.

${ }^{3}$ See the article "Investors Wanted - for Lawsuits" by Linda Himelstein in Business Week (November 15, 1993).
} 
ment materializes. They can do so either explicitly, by undertaking patent litigation insurance (PLI), or tacitly, by holding credit lines that would provide them with the required financial muscle in case of infringement. ${ }^{4}$

The literature on patent protection has studied the influence of litigation (and the threat of using it) on infringement and the settlement agreements reached with potential infringers $5^{5}$ Existing studies make clear that the effective protection of the innovation depends on the willingness of both parties to go to court, which involves different trade-offs. First, if the expected profits of the prospective entrant exceed the costs of litigation (or the expected licensing fees resulting from pre-trial settlement), infringement will occur. Second, patentees will defend their rights if the expected net profits from litigating exceed those of accommodating the infringement. When this condition does not hold, the potential infringer will correctly anticipate that there will be no legal response to its entry and, then, patent predation will arise: the infringer will enter irrespectively of the strength that its case would have had in court.

The objective of this paper is to reexamine these arguments after considering the issue of litigation financing, so far neglected in the literature, which implicitly assumes that both the innovator and its rival pay for their litigation costs with internal funds. In our model, an incumbent firm, which relies on external financing, faces the threat of infringement of its patent by a deep-pocketed rival firm. The infringement consists in entering the market with a closely related product and the incumbent must decide how to source funding for litigating it, if necessary. We consider various ex-ante (prior to the infringement) and ex-post (following the infringement) arrangements for the financing of the incumbent's litigation costs. We analyze the influence of the terms

\footnotetext{
${ }^{4}$ The use of PLI among US innovators took off during the 1990s, although PLI is a still small, highly specialized business so far concentrated in a few insurance carriers (see Betterley, 2004). In Europe, the market for PLI is less developed and the European Commission is studying policies for its promotion - see http://europa.eu.int/comm/internal_market/en/indprop/patent/litigation.htm.

${ }^{5}$ Meurer (1989) and Aoki and $\mathrm{Hu}$ (1999) analyze the issue of settlement conditional on infrigement and its relationship with the quality of the innovation and patent breadth. Crampes and Langinier (2002) and Llobet (2003) look at the infringement decision of the rival as affected by the prospective reaction of the incumbent.
} 
in which litigation costs are financed on the incumbent's willingness to litigate and, through it, on the outcome of the patent defense game.

The main contribution of the paper is to show that, absent any other imperfection, the external financing of litigation never worsens and actually has the potential to ameliorate the patent predation problem. In a nutshell, what really matters for patent predation deterrence are the incumbent's incentives to litigate at the margin (that is, for the weakest cases for which it will sue the infringer). Better financing conditions make the incumbent more willing to litigate and hence discourage the rival firm from entering over a larger range of cases. If the financing conditions are set ex-post (and absent other imperfections), Modigliani-Miller logic applies and the situation is just equivalent to internal financing. In contrast, ex-ante external financing (PLI, exante leverage) allows the incumbent to credibly commit to defend the patent over a larger range of cases. The commitment effect comes from the possibility of properly presetting the terms in which litigation would be financed at the margin.

When the legal costs are large relative to the monopoly rents that the incumbent obtains from the patent, ex post financing is associated with patent predation 6 Suppose that, instead, the incumbent obtains from an insurer, in exchange for a premium, what the PLI industry calls "infringement abatement coverage", that is, the coverage of all or part of the litigation costs of the patentee if infringement occurs. Clearly, a policy with full coverage would provide the incumbent with an unconditional commitment to litigate. This commitment would deter the rival from entering the market unless its probability of winning in court were large enough. Under full coverage, however, the incumbent does not internalize ex-post the cost of going to court and, thus, litigates in excess, even when the value of defending the patent (that is, the expected net profits that litigation yields to the coalition formed by the incumbent and the insurer) is negative. So full coverage induces wasteful litigation.

\footnotetext{
${ }^{6}$ In the Appendix we analyze the complementary case in which litigation cost are small relative to the monopoly rents associated with the patent.
} 
We show that wasteful litigation can be fully prevented (without losing on the entry deterrence dimension) by introducing an optimal deductible or co-payment in the PLI policy. Specifically, PLI can achieve the incumbent's second-best outcome (no predation and no excessive litigation) by leaving a part of the litigation-related financial needs uncovered. Interestingly, the same outcome can be reached if, instead of taking explicit PLI, the incumbent guarantees the financing of its litigation costs through ex-ante debt financing. The idea here is to ex-ante structure the conditions of a loan, a loan commitment or a line of credit (partially or totally covering future litigation needs) so as to induce the desired level of aggressiveness in the incumbent's response to a potential infringement.

In sum, since patent predation arises when the patentee is not expected to litigate the infringement, strategies that provide a credible commitment to litigate can prevent infringement and increase the returns from innovation. Arguably, innovators with a large patent portfolio could alternatively rely on building a reputation of fighting infringers, as in Choi (1998). Small innovators, instead, may need institutions such as PLI or credit lines in order to establish an equally powerful commitment to litigate 7 In fact, standard corporate finance theory provides reasons to conjecture that small innovators might prefer PLI rather than solutions based on leverage since debt financing might handicap the undertaking of their, presumably important, growth opportunities (Myers, 1977) $!^{8}$

The interaction between financial structure and product market competition makes our work related to the literature started by Brander and Lewis (1986) and Maksimovic (1986). These papers focus on the strategic use of capital structure-namely

\footnotetext{
${ }^{7}$ Lerner (1995) finds that small firms tend to patent away from lines of business where large firms are more established.

${ }^{8}$ This point is consistent with the view of practitioners such as John Egan and Ray Lupo in the article "Protecting Venture Investments Against Patent Litigation" (Venture Capital Journal, December 2002). In the words of attorney Richard Wilder at a meeting of the World Intellectual Property Organization, "all businesses can benefit from patent protection, but small businesses can't survive without it" (see http://www.wipo.org/sme/en/activities/meetings/pdf/ip_mil01_1b.pdf).
} 
its use by firms as a commitment to compete more or less aggressively with their rivals. Bolton and Scharfstein (1990) emphasize the other side of the coin, showing that firms which rely heavily on external financing may be vulnerable to predatory pricing from their financially stronger competitors. In our setup, external financing has strategic value since it helps to deter patent predation. The strategic value of financial structure appears also in Perotti and Spier (1993), who show that high leverage can pose a firm in a better bargaining position vis-a-vis its more senior creditors, specifically its workers.

In a number of extensions we discuss the robustness of our results to the introduction of settlement, to a change in the legal allocation of litigation costs, and to the presence of a non-competitive credit market. We argue that allowing for settlement would add realism to our predictions about the resolution of the dispute 9 but the rival's entry decision and the incumbent's expected payoffs - the key measures of the incumbent's degree of protection-would not differ substantially from those of the much simpler no-settlement case ${ }^{10}$ We also explain that, although our basic model focuses on a European-type allocation of legal costs (where the loser pays for the costs of the winner), the results are qualitatively identical under a US-type allocation of the costs (where each party pays for its own costs). Yet the comparison of the two systems yields some additional predictions on how the levels of infringement and litigation, and the potential for the use of PLI may differ across countries.

In a final extension, we show that the model can be modified to analyze the case in which a rival firm alleges infringement of its own patent to force the exit of the

\footnotetext{
${ }^{9}$ According to the evidence compiled by Lanjouw and Schankerman (2004), more than $90 \%$ of the patent-infringement suits are settled before the trial concludes.

${ }^{10}$ With settlement, instead of a final court decision that determines a winner and a loser, the parties would tend to agree on a licensing fee which would make each of them obtain their expected litigation proceeds (as in our model) plus some share in the surplus from settlement. Hence, where we predict excessive litigation, settlement might finally prevent it from happening but, importantly, the incumbent would still suffer its cost in the form of a weaker bargaining position and a lower final payoff. So in terms of the incumbent's returns from innovation, the prediction would not be very different. See Section 6.1 for more details.
} 
incumbent 11 This extension provides a rationale for the use of "infringement defense coverage" based on essentially the same logic that justifies PLI in the basic model.

The paper proceeds as follows. In Section 2 we introduce the model. In Section 3 we describe the various ex-post financing scenarios (internal financing, external financing with perfect information and external financing with asymmetric information), while Section 4 is devoted to ex-ante financing (PLI and ex-ante leverage). Section 5 contains our discussion on the robustness of the results. Section 6 makes the case for infringement defense coverage. Section 7 concludes. The Appendix contains the proofs and the analysis of the no-predation case.

\section{The model}

Consider a risk-neutral economy with a competitive credit market in which all agents require an expected rate of return normalized to zero. In a given industry, an incumbent $(i)$ who exploits a patented product faces the risk of entry of a rival $(j)$ with a competing product. If the rival enters, the incumbent must decide whether to litigate in defense of its patent or not. If the incumbent litigates and wins the trial, it preserves its monopoly future revenues of $1+\pi$, while the rival gets no future revenue. If the incumbent decides not to litigate or loses the trial, each firm obtains future revenues of 1 .

Litigation makes both firms incur a cost $c$ at some early date. When the case is resolved, the winner is compensated by the loser for the expense $c 2^{12}$ The uncertainty about the outcome of litigation is parameterized by the probability that the incumbent wins the corresponding trial, $p \in[0,1]$. Intuitively, this probability measures the strength of the incumbent's case relative to the rival's, summarizing the criteria used

\footnotetext{
${ }^{11}$ This type of suits are very frequent in the US. Preventing them is put forward by Jaffe and Lerner (2004) as a main motivation for their proposals of reform of the US patent system.

${ }^{12}$ This allocation of litigation costs is consistent with the British legal system. In most Continental Europe, the same allocation follows except if the court rules only partially in favor of one of the parties. The US cost allocation, where each party pays its own costs, is analyzed in Subsection 6.2.
} 
by courts to assess whether the patent is valid and has been infringed (that is, the relative quality and originality of the invention, the similarity between the patented and the competing products, the documented innovative efforts of each party, etc.).

We assume that there is some initial uncertainty about the strength of the patent, $p$, characterized by a known distribution function $G(p)$ and an associated probability density function $g(p)>0$. This uncertainty can be interpreted as the result of initially ignoring the precise nature of the rival's competing product. Hence we assume that $p$ is privately observed by the rival right before entering and by the incumbent once the rival enters.

Both firms are initially 100\%-equity financed and maximize their shareholders' expected net payoffs. We assume that, in case of litigation, the legal process obliges both firms to incur their litigation costs in advance and to guarantee the compensation of litigation expenses to the other firm if it wins the trial (say, by establishing a safe deposit or by obtaining a guaranty from a solvent third party). To focus on the financing problems of the incumbent, we assume that the rival meets its litigationrelated expenses with internal funds. As for the incumbent, we consider several alternatives for the ex-post or ex-ante coverage of its litigation needs:

1. Ex-post financing refers to the situation in which the incumbent makes no financial arrangement prior to the entry of the rival. We first analyze, as a benchmark, the case in which the incumbent possesses sufficient internal funds to self-finance its litigation. By the logic of the Modigliani-Miller propositions, this situation is actually equivalent to not having any internal funds and to rely on outside financiers who, once the rival enters, observe the patent strength parameter $p$ and compete for covering the incumbent's financial needs (perfect information scenario). Finally, we look at a third situation in which the incumbent does not have any internal funds and the outside financiers do not observe the patent strength parameter $p$ (asymmetric information scenario) 
2. Ex-ante financing refers to the situation in which the incumbent makes some strategic financial arrangement prior to the entry of the rival (and the realization of $p$ ). We first analyze the possibility of subscribing patent litigation insurance (PLI), that is, the contingent coverage of infringement abatement litigation, with one of the competing outside financiers. Then we look at other ex-ante arrangements, based on leverage, that allow the incumbent to anticipatively raise some or all the funds required for its potential future litigation. We will examine to which extent these arrangements provide a good substitute for PLI.

\begin{tabular}{|c|c|c|c|c|}
\hline$t=0$ & $\mathrm{t}=1$ & $t=2$ & $t=3$ & $\mathrm{t}=4$ \\
\hline & + & & & \\
\hline $\begin{array}{l}\text { PLI possibly } \\
\text { arranged }\end{array}$ & $\begin{array}{l}\mathrm{p} \text { realizes } \\
\text { Rival decides } \\
\text { on entry }\end{array}$ & $\begin{array}{l}\text { If entry, incumbent } \\
\text { decides on } \\
\text { litigation and, } \\
\text { possibly, ex-post } \\
\text { financing }\end{array}$ & $\begin{array}{l}\text { If litigation, } \\
\text { trial occurs }\end{array}$ & $\begin{array}{l}\text { Final payoffs } \\
\text { assigned }\end{array}$ \\
\hline
\end{tabular}

Figure 1: The timing of events

The timing of the decisions on litigation financing is shown in Figure 1 together with the remaining events in the model. To make the discussion non-trivial, we assume:

$$
2 c>1
$$

This assumption establishes that the firm that loses the trial incurs overall litigation expenses that exceed its future revenues, which means that, if a firm has (or is perceived to have) a sufficiently high probability of losing the trial, it will be unwilling or unable to litigate. Conversely, since litigation costs fall eventually on the loser, if firm has (or is perceived to have) sufficiently high chances of winning the trial will be willing and able to litigate. 


\section{Ex-post financing}

In this section we analyze the situation in which the incumbent makes no financial arrangement prior to the entry of the rival. To set a benchmark, we start with the case in which the incumbent possesses sufficient internal funds to self-finance its litigation. This scenario can be described as a sequential game with the following structure. First nature selects a realization of the patent-strength parameter $p$ which is observed by the incumbent and its rival. After observing $p$, the rival decides whether to enter or not. If there is entry, the incumbent decides whether to litigate or not. Both players finance internally their litigation expenses (that is, their initial litigation $\operatorname{cost} c$ plus the compensation of $c$ to the other party if they lose). The net payoffs of the players in the different possible final nodes of this game are summarized in Table 1.

\section{Table 1: Internal financing payoffs}

\begin{tabular}{lcc} 
& \multicolumn{2}{c}{ Net payoffs } \\
\cline { 2 - 3 } Final node & Rival & Incumbent \\
\hline \hline No entry: & 0 & $1+\pi$ \\
\hline Entry, no litigation: & 1 & 1 \\
\hline Entry, litigation & & \\
$\quad$ - Incumbent wins (prob. $p$ ): & $-2 c$ & $1+\pi$ \\
$\quad$ - Incumbent loses (prob. $1-p$ ): & 1 & $1-2 c$ \\
\hline \hline
\end{tabular}

In order to characterize the equilibrium of this game under each possible realization of $p$, we proceed by backward induction. The incumbent's expected net payoff from litigating is $p(1+\pi)+(1-p)(1-2 c)$, while its net payoff from not litigating is 1. So the incumbent will litigate if and only if

$$
p \geq p_{i} \equiv \frac{2 c}{\pi+2 c} .
$$

Now, the rival will clearly enter for all $p<p_{i}$, since it will anticipate that the incumbent will not litigate for those values of $p$. Instead for $p \geq p_{i}$, the rival will compare 
its expected payoff from entering, $p(-2 c)+(1-p)$, with the payoff from staying out, which is 0 . So it will enter if and only if 13

$$
p<p_{j} \equiv \frac{1}{2 c+1} \text {. }
$$

Of course, the double condition $p \geq p_{i}$ and $p<p_{j}$ for observing entry followed by litigation can only be satisfied if $p_{j}>p_{i}$ or, equivalently, if $\pi>4 c^{2}$. This allows us to conclude that:

Proposition 1 In the internal financing scenario, if $\pi \leq 4 c^{2}$, entry occurs for $p \in$ $\left[0, p_{i}\right)$ and is never followed by litigation. If $\pi>4 c^{2}$, entry occurs for $p \in\left[0, p_{j}\right)$ and is followed by litigation for $p \in\left[p_{i}, p_{j}\right)$.

Thus, if $\pi \leq 4 c^{2}$, the level of entry is determined by the incumbent's marginal incentive to litigate, which is weak when the monopoly rent $\pi$ is small relative to the litigation cost $c$. Figure 2 describes the equilibrium outcome over the various ranges of values of the patent strength parameter $p$. For $p \in\left[p_{j}, p_{i}\right)$ entry occurs despite the infringer would have few chances in court, simply because it anticipates that the incumbent will not litigate. We will refer to this phenomenon as patent predation. In equilibrium no litigation occurs. Entry depends (through $p_{i}$ ) negatively on the monopoly rent $\pi$ and positively on the litigation $\operatorname{cost} c$.

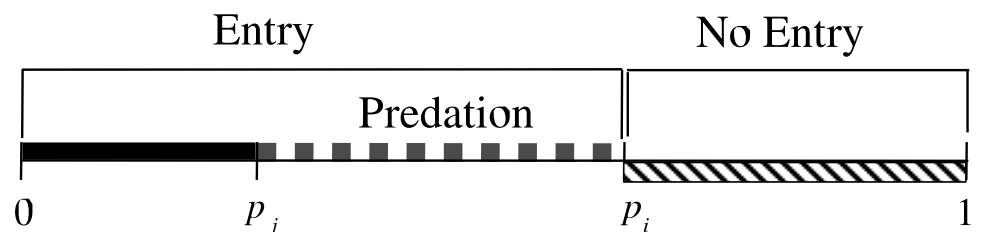

Figure 2: The patent predation case

\footnotetext{
${ }^{13}$ To avoid ties, we will assume throughout the paper that, whenever indifferent about their corresponding decisions, the rival does not enter and the incumbent litigates.
} 
In contrast, if $\pi>4 c^{2}$, due to the large monopoly rents, the incumbent is willing to litigate the infringement over part of the range in which the rival is willing to enter even in the face of litigation. So entry occurs whenever the rival estimates that it would be worth defending its case in court and not because it anticipates that the incumbent will accommodate the entry. No patent predation occurs. Figure 3 shows the equilibrium outcome over the various ranges of values of $p$. The incumbent's incentive to litigate determines the lower bound of the non-empty litigation range, $\left[p_{i}, p_{j}\right)$. This range expands from below when the monopoly rent $\pi$ increases and shrinks from both extremes when the litigation cost $c$ increases.

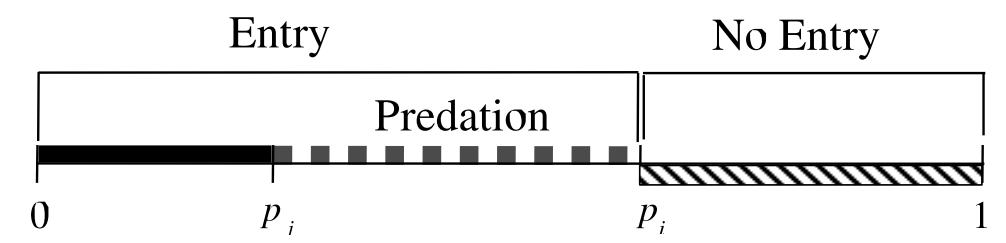

Figure 3: The no predation case

Expectedly, the conditions upon which the incumbent finances its litigation (either ex-post or ex-ante arranged) will affect the incumbent's willingness (or capacity) to litigate, $p_{i}$, but not the rival's willingness to enter in the face of litigation, $p_{j}$. In this sense, one can correctly anticipate that patent litigation financing will affect the level of infringement in the patent predation case $\left(\pi \leq 4 c^{2}\right)$ but not in the no-predation case $\left(\pi>4 c^{2}\right)$. Given this and for brevity, the rest of discussion in the body of the paper will focus on the former case, relegating the analysis of the latter to the Appendix.

\subsection{External financing}

By external financing we mean a situation in which a third party provides the incumbent with both the early funding of the litigation cost $c$ and the guaranty of the 
compensation to be paid to the rival if the trial is lost. We will refer to this party as the financier, who, depending on the precise nature of its intervention might be interpreted as a bank, a venture capitalist or an insurance company. Financiers proceed from the credit market that we have assumed to be competitive and characterized by a zero required rate of return. Since we have $2 c>1$, the incumbent's future returns if it loses the trial are insufficient to repay the early litigation cost $c$ to the financier and to compensate the rival for its own litigation cost. Thus we assume that the financier covers both and, in exchange, is offered a repayment $R$ in case the trial is won and all the incumbent's future revenue if the trial is lost ${ }^{14}$ In this sense, $R$ can be interpreted as the face value of some (risky) loan used for the funding of the early expense $c .15$

To describe the external financing game, we must modify the game described in the previous subsection by adding a new, financing stage - after the rival enters and before the incumbent starts the litigation, in which $R$ is set - and a new player - the financier. Table 2 shows the net payoffs of the three players in the final nodes of this game.

\footnotetext{
${ }^{14}$ The form of this contract implies no loss of generality. In the perfect information scenario below, it is immediate to check that the outcome of the game would be equivalent under any alternative break-even contract that requires some repayment $R^{\prime}>R$ if the trial is won and allows the incumbent to retain part of the future revenue if the trial is lost. For the asymmetric information scenario, see footnote 17 .

${ }^{15}$ Actually, if $c<1$, the contract between the financier and the incumbent can be implemented using straight debt - without explicit reference to the financier's commitment to compensate the rival when it wins. The idea is that, if the trial is lost, the financier will assume such a compensation as a "liability" attached to the "assets" (future revenue) appropriated from the insolvent incumbent.
} 
Table 2: External financing payoffs

\begin{tabular}{lccc} 
& \multicolumn{3}{c}{ Net payoffs } \\
\cline { 2 - 4 } Final node & Rival & Incumbent & Financier \\
\hline \hline No entry: & 0 & $1+\pi$ & 0 \\
\hline Entry, no litigation: & 1 & 1 & 0 \\
\hline Entry, litigation & & & \\
$\quad$ - Incumbent wins (prob. $p$ ): & $-2 c$ & $1+\pi+c-R$ & $R-c$ \\
$\quad$ - Incumbent loses (prob. $1-p$ ): & 1 & 0 & $1-2 c$ \\
\hline \hline
\end{tabular}

\subsubsection{The perfect information scenario}

When the financiers observe the patent-strength parameter $p$ at the financing stage, one can readily anticipate, by virtue of the standard Modigliani-Miller propositions, that the outcome will coincide with that of the internal financing benchmark. Yet, for completeness, we will briefly go through the details of the analysis. Clearly, since $p$ is observable to the financiers, competition will push the repayment $R$ down to the value in which the financier breaks even, that is:

$$
p(R-c)+(1-p)(1-2 c)=0 .
$$

This equation defines a decreasing function $R(p)$ that yields the repayment required for financing litigation at each value of $p$. For a given $p$, the incumbent will be willing to litigate if and only if $p[1+\pi+c-R(p)] \geq 1$, where the first term is the expected payoff from litigating and the second is the payoff from not litigating. Using the expression for $R(p)$ that arises from (4), it turns out that, indeed, the above condition boils down to $p \geq p_{i}$, exactly like in the internal financing case ${ }^{16}$ Hence, as anticipated:

\footnotetext{
${ }^{16}$ Additionally, one can check that the feasibility constraint $R(p) \leq 1+\pi+c$ holds with equality at precisely $p=p_{i}$ and with inequality for all $p>p_{i}$.
} 
Proposition 2 Under perfect information and $\pi \leq 4 c^{2}$, ex-post external financing leads to the same outcome as internal financing: entry occurs for $p \in\left[0, p_{i}\right)$ and is never followed by litigation.

The intuition for this result is that under $R(p)$ the incumbent is the residual claimant of the ex-post net litigation gains and so decides whether to litigate exactly as in the internal financing benchmark. Hence, the decisions of the rival do not change and patent predation persists.

\subsubsection{The asymmetric information scenario}

Suppose now that financiers do not observe the patent-strength parameter $p$, while in all other respects, the game remains the same as in the previous subsection. Because of the informational asymmetry, financiers set the repayment $R$ demanded in exchange for the coverage of the incumbent's litigation-related needs on the basis of some beliefs about the range of values of $p$ for which the rival might have entered and the incumbent wants to litigate. ${ }^{17}$

In order to characterize the equilibrium in this situation, let $R$ denote the (lowest) repayment demanded by financiers after observing entry. If entry occurs for some $p$, the incumbent's payoff from litigating is $p(1+\pi+c-R)$, while the payoff from not litigating is 1 , so the incumbent will litigate if and only if

$$
p \geq \bar{p}(R) \equiv \frac{1}{1+\pi+c-R}
$$

Hence, if financiers expect entry for all $p \in\left[0, p_{f}\right)$, they will expect to induce litigation for $p \in\left[\bar{p}(R), p_{f}\right)$ if $\bar{p}(R)<p_{f}$, and to keep the incumbent away from litigation if $\bar{p}(R) \geq p_{f}$. Thus the financier's expected net payoff can be written as

\footnotetext{
${ }^{17}$ By focusing on risky debt contracts parameterized by $R$ we are not ruling out any interesting screening possibility. Clearly, an alternative contract that requires some repayment $R^{\prime}>R$ if the trial is won and allows the incumbent to retain part of the future revenue if the trial is lost would be more attractive to the incumbent (relative to the benchmark contract) the lower is $p$, so it would not be helpful in inducing the use of the contract for larger values of $p$.
} 


$$
\Pi\left(R, p_{f}\right)= \begin{cases}p^{e}\left(R, p_{f}\right)(R-c)+\left[1-p^{e}\left(R, p_{f}\right)\right](1-2 c), & \text { if } \bar{p}(R)<p_{f} \\ 0, & \text { if } \bar{p}(R) \geq p_{f}\end{cases}
$$

where $\left.p^{e}\left(R, p_{f}\right) \equiv E\left[p \mid \bar{p}(R) \leq p<p_{f}\right]\right|^{18}$ Competition between financiers means that in equilibrium there should exist no repayment different from $R$ under which a deviating financier could make higher profits 19

The rival will decide on entry anticipating the equilibrium repayment. Clearly, for $p<\bar{p}(R)$, the rival will expect no opposition and, thus, will enter, while, for $p \geq \bar{p}(R)$, the rival will decide exactly as in the internal financing case, entering if and only if $p<p_{j}$.

We now have all the ingredients to obtain the following result, proven in the Appendix.

Proposition 3 With asymmetric information and $\pi \leq 4 c^{2}$, there is a continuum of equilibria with ex-post financing, indexed by $x \in\left[p_{j}, p_{i}\right]$, in which entry occurs for $p \in[0, x)$ and is never followed by litigation.

Intuitively, each of the various levels of entry that can be sustained in equilibrium are supported by a system of expectations of the rival and the financiers, and a financial contract whose terms are consistent with those expectations. Lower entry is associated with a lower repayment $R$. Whenever the anticipated $R$ is such that $\bar{p}(R) \geq$ $p_{j}$, the potential infringer will abstain from entering for all $p \geq \bar{p}(R)$, confirming the expectations that justify the terms offered by the financiers. However, this selffulfilling patent predation deterrence can only operate within some limits. Entry deterrence cannot extend to points in which the entrant is willing to enter even in the face of litigation (that is, for $p<p_{j}$ ) and it cannot fail to happen in points in which

\footnotetext{
${ }^{18}$ From the financier's perspective, values of $R$ such that $\bar{p}(R) \geq p_{f}$ are equivalent to offering no financing at all. From the perspective of the whole game, however, having financiers willing to offer financial support to the incumbent (at some $R$ ) is key for entry deterrence.

${ }^{19}$ This requirement will imply that the financier offering $R$ breaks even.
} 
litigating upon entry yields strictly positive expected net gains to the incumbent and its ex-post financier (that is, for $p>p_{i}$ ). So the entry threshold $x$ is bound to the interval $\left[p_{j}, p_{i}\right]$.

Importantly, the highest entry threshold sustainable under asymmetric information coincides with the entry threshold under perfect information (and in the internalfinancing benchmark). So external financing never weakens (and has the potential to strengthen) the competitive position of the incumbent. Nevertheless, external financing can only strictly improve the position of the incumbent under the right system of self-fulfilling predation-deterrence expectations. So patent predation deterrence based on asymmetric information is fragile. The ex-ante arrangements analyzed in the next section provide more robust mechanisms for patent predation deterrence.

\section{Ex-ante financing}

By ex-ante financing we mean a situation in which the incumbent makes some financial arrangement prior to the entry of the rival (and the realization of $p$ ). Expectedly, these arrangements may have strategic value, that is, may induce a change in the behavior of the rival that eventually benefits the incumbent. In fact, our prior analysis makes clear that no mechanism can prevent entry for $p<p_{j}$ and also that if the rival anticipates litigation for $p \geq p_{j}$, then entry will occur up to just $p_{j}$. Moreover, because $p_{j}<p_{i}$, litigating for $p<p_{j}$ would be overall unprofitable to the coalition formed by the incumbent and its ex-ante financiers. Hence, the best outcome that the incumbent can hope to achieve by contracting with a financier (the incumbent's second-best outcome) is one in which entry occurs up to just $p_{j}$ and no litigation takes place. In the remaining of this section we constructively show that this second-best outcome can be implemented through patent litigation insurance as well as other ex-ante arrangements based on leverage.20

\footnotetext{
${ }^{20}$ Formally, the proof boils down to showing that both mechanisms allow the incumbent to establish a credible threat of litigation for just $p \geq p_{j}$.
} 


\subsection{Patent litigation insurance}

With patent litigation insurance (PLI), financiers' intervene earlier in the game, before $p$ realizes and the rival decides on entry. They compete in order to offer to the incumbent the contingent coverage of its litigation-related financial needs. We consider PLI policies in which, if litigation occurs, the insurer commits to pay the incumbent's litigation cost $c$ as well as the later compensation to the rival for its own $c$ in case of losing the trial.

Actually, as it turns out, keeping the incumbent away from litigation for $p<p_{j}$ will require that the PLI policy incorporates a deductible or co-payment - a part of the legal costs to be charged to the incumbent. However, since the incumbent's internal funds are zero, we assume that both the premium $P$ and the deductible $D$ of the PLI policy are postponable, which in turn leaves both payments potentially subject to default ${ }^{21}$ Table 3 shows the net payoffs of the three players in this game. The expressions take into account the possibility of defaulting on $P$ or $P+D$, as applicable, if future revenue is lower than them (in which case the insurer appropriates the incumbent's whole future revenue).

\section{Table 3: Patent litigation insurance payoffs}

\begin{tabular}{lccc} 
& \multicolumn{4}{c}{ Net payoffs } \\
\cline { 2 - 4 } Final node & Rival & Incumbent & Insurer \\
\hline \hline No entry: & 0 & $\max \{1+\pi-P, 0\}$ & $\min \{P, 1+\pi\}$ \\
\hline Entry, no litigation: & 1 & $\max \{1-P, 0\}$ & $\min \{P, 1\}$ \\
\hline Entry, litigation & & & \\
$\quad$ - Incumbent wins (prob. $p$ ): & $-2 c$ & $1+\pi+c-P-D$ & $P+D-c$ \\
$\quad$ - Incumbent loses (prob. $1-p):$ & 1 & $\max \{1-P-D, 0\}$ & $\min \{P+D, 1\}-2 c$ \\
\hline \hline
\end{tabular}

\footnotetext{
${ }^{21}$ Since the insurer requires the same expected rate of return as any other financier and plays no active role once the contract is signed, an insurance policy with a postponed premium $P$ and a postponed deductible $D$ is equivalent to combining a policy in which the premium and the deductible are not postponable with the explicit external financing, ex-ante and ex-post, respectively, of both of them.
} 
In order to fix ideas, we briefly discuss the equilibrium of the PLI game in the case without a deductible, $D=0$. Proceeding by backwards induction, suppose that a policy with a premium $\left.P\right|_{D=0}$ is already in place and suppose the rival has entered. As it follows from the net payoffs shown in Table 4, the incumbent will litigate for all values of the patent-strength parameter $p$. But, then, the rival will enter for just $p<p_{j}$, as already derived in (3), implementing the second-best level of entry. The problem, however, is that the incumbent is willing to litigate over the whole entry range, $p \in\left[0, p_{j}\right)$, and thus there will be wasteful litigation in equilibrium and the premium $\left.P\right|_{D=0}$ will have to be large in order to compensate the insurer for the expected litigation costs ${ }^{22}$

Ideally, the incumbent would like to secure the patent-predation deterrence effect without incurring the costs of excessive litigation and this can be accomplished by setting the deductible $D$ at an adequate level. In fact, as the incumbent's second-best outcome involves no litigation in equilibrium, the optimal policy may carry a premium of zero, $P=0$. Under such premium, it is clear from Table 3 that, conditional on entry and the realization of $p$, the incumbent will litigate if and only if its expected net payoff from litigating, $p(1+\pi+c-D)+(1-p) \max \{1-D, 0\}$, exceeds the unit payoff from not litigating or, equivalently, for

$$
p \geq \widetilde{p}(D) \equiv \frac{1-\max \{1-D, 0\}}{1+\pi+c-D-\max \{1-D, 0\}} .
$$

Thus, the second-best can be implemented by setting the deductible so as to have $\widetilde{p}(D)=p_{j}$. Using (3) and (8), it is then immediate to verify that:

\footnotetext{
${ }^{22}$ Specifically, the premium $\left.P\right|_{D=0}$ will have to satisfy the break-even condition:

$$
\int_{0}^{p_{j}}[p(P-c)+(1-p)(\min \{P, 1\}-2 c)] g(p) d p+\left[1-G\left(p_{j}\right)\right] \min \{P, 1+\pi\}=0,
$$

where the first term in the LHS corresponds to the part of the insurer's expected net payoff generated over realizations of $p$ followed by entry and litigation, while the second term corresponds to the part generated from the premium collection when no entry occurs. Since the LHS is strictly increasing in $P$, equation (7) has a unique solution, which is meaningful if it does not exceed $1+\pi+c$.
} 
Proposition 4 With $\pi \leq 4 c^{2}$, the incumbent's second-best outcome can be implemented by a PLI policy with a zero premium and a postponed deductible of $D=\pi-c \geq$ 1 if $c \leq \pi-1$ and $D=\frac{\pi+c}{2 c+1}<1$ if $c>\pi-1$.

Importantly, in spite of its piecewise definition, the optimal deductible is a continuous, monotonic function of the parameters $\pi$ and $c$. Intuitively, $D$ is increasing in the monopoly rent $\pi$ because, other things equal, $\pi$ increases the incumbent's tendency to litigate (reduces $\widetilde{p}(D)$ ), while the second-best threshold $p_{j}$ (which reflects the rival's willingness to confront litigation) is invariant to $\pi$. Similarly, $D$ is decreasing in the litigation cost $c$ because, other things equal, increasing $c$ reduces the rival's incentive to enter in the face of litigation, $p_{j}$, by more than it increases the incumbent's tendency to litigate (reduces $\widetilde{p}(D))$.

\subsection{Ex-ante leverage}

We now turn to analyze whether the incumbent's second best can also be implemented by ex-ante setting the conditions of a loan that partially or totally covers its future litigation-related financial needs. We consider arrangements whereby, before $p$ realizes and the rival decides on entry, the incumbent borrows an amount $F$ from one of the financiers (the ex-ante financier).

Table 4 summarizes the net payoffs of the incumbent and its ex-ante financier in a situation with $F \geq 2 c$ (and thus $F>1$ ) - the alternative situation with $F<2 c$ will be examined immediately afterwards. We assume that the incumbent keeps $2 c$ safe for the potential financing of litigation and distributes $F-2 c$ as a dividend among its shareholders (so this arrangement corresponds to what is commonly known as a leverage recapitalization). In exchange for $F$, the ex-ante financier receives a claim $R_{1}$ (which we assume without loss of generality lower than $1+F$ ) on the incumbent's future revenue ${ }^{23}$ For brevity, we omit the payoffs of the rival, which are the same as

\footnotetext{
${ }^{23}$ In fact, the analysis below shows that the incumbent's second best can generally be implemented with $R_{1}=F<1+F$.
} 
in previous scenarios, as well as the dividend-part of the incumbent's payoff, which would simply add a constant $F-2 c$ to each of the final nodes.

Table 4: Ex-ante leverage payoffs with $F \geq 2 c$

\begin{tabular}{lcc} 
& \multicolumn{2}{c}{ Net payoffs } \\
\cline { 2 - 3 } Final node & \multicolumn{2}{c}{$\begin{array}{c}\text { Ex-ante } \\
\text { financier }\end{array}$} \\
\hline \hline No entry: & $1+\pi+2 c-R_{1}$ & $R_{1}-F$ \\
\hline Entry, no litigation: & $1+2 c-R_{1}$ & $R_{1}-F$ \\
\hline Entry, litigation & & \\
- Incumbent wins (prob. $p$ ): & $1+\pi+2 c-R_{1}$ & $R_{1}-F$ \\
- Incumbent loses (prob. $1-p$ ): & 0 & $1-F$ \\
\hline \hline
\end{tabular}

To check the possibility of implementing the incumbent's second best with some $F \geq 2 c$, notice first that the financier's break-even condition would imply $R_{1}=F$ since the second best involves no litigation in equilibrium. With $R_{1}=F$, Table 4 makes clear that, conditional on entry, the incumbent would litigate if and only if $p(1+\pi+2 c-F) \geq 1+2 c-F$, that is, for

$$
p \geq \widehat{p}(F) \equiv \frac{1+2 c-F}{1+\pi+2 c-F} .
$$

Thus getting $\widehat{p}(F)=p_{j}$ would require, from (3), setting $F=1+2 c-\frac{\pi}{2 c}$. This expression is compatible with the initial assumption $F \geq 2 c$ if and only if $\pi \leq 2 c$.

Let us now turn to the situation with $F<2 c$, whose payoffs are described in Table 5. Suppose that the incumbent keeps the whole $F$ safe for the potential financing of litigation and, once needed, looks for a second, ex-post financier willing to cover the difference $2 c-F$ in case it loses the trial. As above, the ex-ante financier receives a claim $R_{1}$ on the incumbent's future revenue, while the ex-post financier, if needed, receives a claim $R_{2}$ junior to $R_{1}{ }^{24}$ The payoffs of the incumbent and its ex-ante and

\footnotetext{
${ }^{24}$ Clearly, the ex-ante arrangement can also be interpreted as a loan commitment or a line of credit that the incumbent only uses if it decides to litigate.
} 
ex-post financiers are written for the relevant case with $F>1$ and $R_{1}<1+F{ }^{25}$

Table 5: Ex-ante leverage payoffs with $F<2 c$

\begin{tabular}{lccc} 
& \multicolumn{3}{c}{ Net payoffs } \\
\cline { 2 - 4 } Final node & Incumbent & $\begin{array}{c}\text { Ex-ante } \\
\text { financier }\end{array}$ & $\begin{array}{c}\text { Ex-post } \\
\text { financier }\end{array}$ \\
\hline \hline No entry: & $1+\pi+F-R_{1}$ & $R_{1}-F$ & 0 \\
\hline Entry, no litigation: & $1+F-R_{1}$ & $R_{1}-F$ & 0 \\
\hline Entry, litigation & & & \\
- Incumbent wins (prob. $p$ ): & $1+\pi+F-R_{1}-R_{2}$ & $R_{1}-F$ & $R_{2}$ \\
- Incumbent loses (prob. $1-p):$ & 0 & $1-F$ & $-(2 c-F)$ \\
\hline \hline
\end{tabular}

For expositional simplicity, we focus on the scenario in which the ex-post financier observes $p$, but the results would be same if ex-post financing were arranged under asymmetric information. The ex-post financier's repayment $R_{2}$, fixed after the realization of $p$, must satisfy the break-even condition $p R_{2}-(1-p)(2 c-F)=0$. This condition determines $R_{2}$ as a function of $p$ and $F$ :

$$
R_{2}=R(p, F) \equiv \frac{(1-p)(2 c-F)}{p} .
$$

On the other hand, as the second best involves no litigation in equilibrium, the exante financier's break-even condition would again imply $R_{1}=F$. With $R_{1}=F$ and $R_{2}=R(p, F)$, Table 5 makes clear that, conditional on entry, the incumbent would litigate if and only if $p[1+\pi-R(p, F)] \geq 1$, that is, for

$$
p \geq \widehat{p}(F) \equiv \frac{1+2 c-F}{1+\pi+2 c-F}
$$

exactly as in $(9)$. Thus getting $\widehat{p}(F)=p_{j}$ would again require setting $F=1+2 c-\frac{\pi}{2 c}$, which is compatible with the assumption $F<2 c$ if and only if $\pi>2 c$.

\footnotetext{
${ }^{25}$ It would be immediate to prove that in an arrangement with $F<1$, the presence of ex-ante financing would not modify the litigation decisions of the incumbent (and hence the entry and litigation outcomes) relative to the ex-post internal financing benchmark. Additionally, the analysis below shows that the incumbent's second best can be implemented with $R_{1}=F<1+F$.
} 
Clearly, the situations with $F \geq 2 c$ and $F<2 c$ cover the whole spectrum of parameters for the patent predation case $\left(\pi \leq 4 c^{2}\right)$. The results can be summed up as follows:

Proposition 5 With $\pi \leq 4 c^{2}$, the incumbent's second-best outcome can be implemented by ex-ante borrowing $F=1+2 c-\frac{\pi}{2 c}$. If $\pi \leq 2 c$, the amount $2 c \leq F$ is reserved for the potential financing of litigation and the excess is paid as a dividend. Otherwise, the whole $F<2 c$ is reserved for the potential financing of litigation, which would be complemented with ex-post financing.

In words, the incumbent can use ex-ante leverage in order to optimally fine-tune its level of aggressiveness in the response to a potential infringement. The credible commitment to litigate for all $p \geq p_{j}$ can be attained by establishing beforehand the terms for the financing of (all or part of) the potential litigation expenses. In doing so, limited liability, together with the preset financing terms, plays an important role, as it allocates the upside of litigation (winning in court) to the levered incumbent and its downside (losing in court) to the ex-ante financier, biasing the incumbent towards litigation.

\section{Robustness of the results}

Two main results emerge from the analysis of the various scenarios considered in previous sections. First, either with ex-ante or with ex-post financing, the incumbent's willingness and effective capacity to litigate is never lower than in the internal financing benchmark. In that sense, the lack of internal funds is not a source of patent vulnerability. If anything, external financing, either ex-post, under asymmetric information and with the right set of deterrent beliefs, or ex-ante, with a properly designed PLI or leverage arrangement, can induce the incumbent to defend its patent more aggressively than in the internal financing benchmark. 
Second, from the incumbent's perspective, it is always optimal to deter what we have called patent predation but without inducing excessive litigation. Ex-ante arrangements such as PLI, a leverage recapitalization, or a credit line allow to implement the incumbent's second-best outcome. The incentives of the incumbent to litigate can be fine-tuned through co-payments, the level of ex-ante leverage or the partial reliance on ex-post financing, respectively.

In the remaining of this section we comment on the robustness of these results to changing the model in three important dimensions: (i) allowing the parties to reach a settlement agreement out of court, (ii) allocating the legal costs to each party rather than to the loser, and (iii) introducing a non-competitive (rather than perfectly competitive) credit market.

\subsection{Settlement}

We have argued that abstracting from settlement is a convenient simplification. The idea is that, even if the incumbent and the rival were allowed to bargain in order to settle their dispute and save on litigation costs, the entry decision of the rival and the expected payoffs of the incumbent would not differ much from those of our simpler no-settlement model. It is now time to corroborate this idea by commenting on the modifications that allowing for settlement would introduce. For brevity, we will focus on the perfect information scenario.

Let us suppose that, once the rival enters and before litigation, firms can reach an agreement whereby, in exchange for a positive payment from the rival to the incumbent (say, a licensing fee), the incumbent ceases to oppose to the presence of the rival in the market ${ }^{26}$ The outcome of the negotiations leading to the settlement is formalized as a (possibly asymmetric) Nash bargaining solution. The threat points

\footnotetext{
${ }^{26}$ We do not allow for agreements implying a "reversion to monopoly", that is, agreements whereby the incumbent bribes the rival to induce it to exit the market. In the absence of a court ruling that the original patent right was infringed, this type of agreement might raise antitrust concerns. See Maurer and Scotchmer (2004) for a thorough analysis of these issues.
} 
of each party are determined taking into account that, if the negotiations fail, the situation reverts to what it is in the current no-settlement model.

It turns out that when litigation is financed ex post, the equilibrium outcome preserves most of the features of the current model. Specifically, if the monopoly rent $\pi$ is sufficiently small relative to the litigation $\operatorname{cost} c$ (like in the patent predation case on which we have focused above) and the incumbent's bargaining power is not small, the incumbent prefers accommodating entry to litigating at the relevant entry margin and, thus, the only possible outcome of the negotiation will be the mere accommodation of entry up to the threshold $p_{i}$ - exactly as in the model without settlement. Similarly, when $\pi$ is sufficiently large relative to $c$ (like in the no-predation case discussed in the Appendix), the incumbent would prefer litigation to settlement at and above the entry margin and, thus, the upper entry threshold will be $p_{j}$-again like in the baseline model.

In intermediate cases, settlement introduces some differences. Both when $\pi$ is neither too large nor too small relative to $c$, and when $\pi$ is small relative to $c$ and the incumbent's bargaining power is also small, the prospects of a sufficiently profitable settlement agreement expand the entry range relative to the no-settlement model. This additional entry constitutes another form of patent predation: entry due to the expectation of an attractive settlement agreement. Of course, the settlement agreement allocates part of the savings in litigation costs to the incumbent, partially compensating it for its loss of monopoly rents.

Importantly, the possibility of settlement widens the potential role of patent litigation insurance and the other ex-ante arrangements, since they might also serve to deter entry motivated by the expectation of a "cheap" settlement agreement, as in the intermediate cases mentioned above. Specifically, PLI or ex-ante leverage would raise the payment that the rival must pay if it enters, thus reducing the entry range and increasing the incumbent's settlement payoffs over part of it. While a positive deductible or a proper fine-tuning of the level of leverage would still be needed to 
prevent excessive litigation, the equilibrium deductible (leverage) might actually be smaller (larger) than in the current no-settlement model and induce some ex-post wasteful litigation.

\subsection{US-type allocation of legal costs}

So far, by assuming that the loser compensates the winner for its legal costs, we have addressed the way in which legal expenses are allocated in Britain and most of Continental Europe ${ }^{27}$ In contrast, in the United States and in other countries with a similar legal system, each party pays for its own legal costs 28 In this section we show that our results remain qualitatively unchanged under this alternative cost allocation, although the outcomes are not identical and allow us to draw some interesting conclusions about the comparison between both legal systems ${ }^{29}$

Table 6 describes the payoffs of the internal financing benchmark under a UStype allocation of legal costs. It is immediate to verify that the threshold above which the internally-financed incumbent is willing to litigate is $p_{i}^{U S}=\frac{c}{\pi}$, while the threshold below which the rival is willing to enter even in the face of litigation is $p_{j}^{U S}=\max \{1-c, 0\}$. Hence, the patent predation case $\left(p_{j}^{U S}<p_{i}^{U S}\right)$ emerges if either $c \geq 1$ or $c<1$ and $\pi \leq \frac{c}{1-c}$, that is, again, when litigation costs are large relative to the monopoly rents at stake. With minor modifications, it would be possible to reproduce our previous results for this case. Specifically, external financing under perfect information yields the same outcome as internal financing, while under asymmetric information it may allow to sustain a continuum of equilibria with entry margins in the interval $\left[p_{j}^{U S}, p_{i}^{U S}\right]$. Similarly, it is possible to implement the incumbent's second best outcome (entry up to just $p_{j}^{U S}$, without litigation) via PLI with a

\footnotetext{
${ }^{27}$ Except if the court rules only partially in favor of one of the parties, which is not a possibility in our model.

${ }^{28}$ The main exception corresponds to the so-called frivolous lawsuits, legal challenges without merit in which the plaintiff pays all the costs if it loses.

${ }^{29}$ Bebchuk and Chang (1996) analyze the efficiency of different cost allocation systems in a general litigation model.
} 
proper deductible or with an ex-ante leverage arrangement similar to those described in Proposition 5.

Table 6: Internal financing payoffs when each party pays its own legal costs

\begin{tabular}{lcc} 
& \multicolumn{2}{c}{ Net payoffs } \\
\cline { 2 - 3 } Final node & Rival & Incumbent \\
\hline \hline No entry: & 0 & $1+\pi$ \\
\hline Entry, no litigation: & 1 & 1 \\
\hline Entry, litigation & & \\
$\quad$ - Incumbent wins (prob. $p$ ): & $-c$ & $1+\pi-c$ \\
$\quad$ - Incumbent loses (prob. $1-p$ ): & $1-c$ & $1-c$ \\
\hline \hline
\end{tabular}

To better visualize the main differences between the outcomes associated with what we briefly denote the US legal system and the EU legal system, Figure 4 depicts the internal financing thresholds under both systems as a function of the parameter $\pi$. The thresholds of the baseline model appear as $p_{j}^{E U}$ and $p_{i}^{E U}$. For brevity, the figure focuses on the case with $c<1$.

Several facts can be emphasized. First, for all $\pi$, we have $p_{j}^{\mathrm{US}}<p_{j}^{\mathrm{EU}}$, indicating a lower willingness to enter in the face of litigation (and thus a second best characterized by a lower entry level) in the US system than in the EU system. This ranking results from the fact that at the relevant margin, the EU system implies lower expected litigation costs for the rival ( $2 c$ paid with a probability of losing the trial lower than 1/2) than the US system ( $c$ paid with certainty).

For a symmetric reason, the incumbent is more willing to litigate in the EU system than in the US system $\left(p_{i}^{E U}<p_{i}^{U S}\right)$ if and only if $p_{i}^{E U}$ is smaller than $1 / 2$, which occurs exactly for $\pi<2 c$. Thus, in the absence of ex-ante arrangements that prevent patent predation, the US system would tend to produce greater levels of infringement than the EU system on low value patents (low $\pi$ ), while it would tend to produce lower levels of infringement than the EU system on medium-to-high value patents (high $\pi)$. With the proper ex-ante arrangements, the US system would invariably produce 


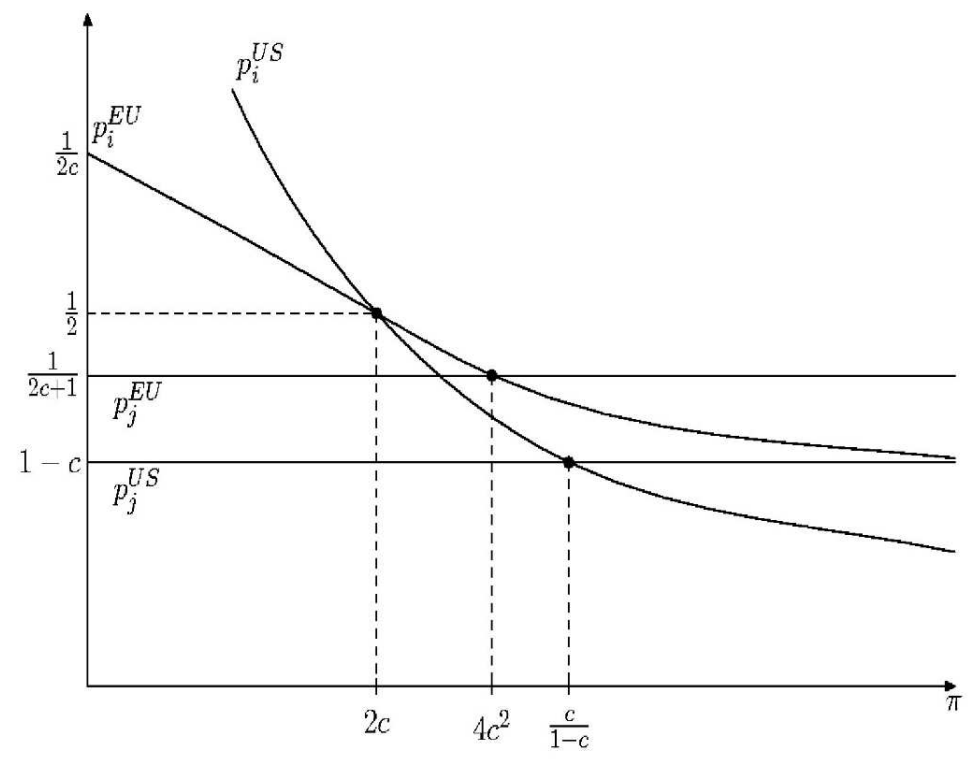

Figure 4: The relevant thresholds across legal systems

lower levels of infringement than the EU system 30

Interestingly, the patent predation case emerges over a wider set of combinations of the parameter $\pi$ and $c$ under the US system than under the EU system. This implies that, other things equal, PLI and the ex-ante arrangements based on leverage would find a broader set of potential users among US innovators than among European innovators. This seems consistent with the fact that the PLI market is more developed in the US than in Europe.

\subsection{Non-competitive credit market}

One might wonder to what extent our previous results hinge on the assumption that the credit market is competitive and, as a result, financiers break even. It turns out that the results remain for the most part unaltered in a less competitive financial market. To illustrate this point, let us briefly consider an alternative structure

\footnotetext{
${ }^{30}$ These predictions suggest a possible avenue for the empirical testing of our theoretical results.
} 
with a monopolistic financier. Clearly, under ex-post financing, if the parameter $p$ is observable to the financier, he will be able to appropriate the whole surplus from litigation. But then litigation - and the implied entry outcome - will be exactly like in the internal financing case, just with a different distribution of the surplus.

If the parameter $p$ is unobservable to the financier, then the resort to a monopolistic ex-post financier affects matters differently across the patent predation $\left(\pi \leq 4 c^{2}\right)$ and no-predation $\left(\pi>4 c^{2}\right)$ cases. In the former, the results outlined in Proposition 3 still hold. In particular, if the financier expects entry up to some $x \in\left[p_{j}, p_{i}\right]$, he will be indifferent between demanding a break-even repayment for its financing or a larger one, since litigation will not arise in equilibrium and thus its profits will be zero anyway. In contrast, in the no-predation case, there is an interval $\left[p_{i}, p_{j}\right)$ of realizations of $p$ in which the rival enters and litigation can yield an overall positive net payoff to the coalition formed by the incumbent and the financier. The analysis in the Appendix shows that the competitive, break-even repayment would induce excessive litigation in this case, since breaking even on expectation means financing litigation at a loss in the margin. The repayment required by a monopolistic financier, instead, will never induce litigation for realizations of $p$ where he makes losses. In fact, in order to extract higher profits from higher realizations of $p$, the required repayment may be such that some overall profitable litigation opportunities are passed up 41 This effect captures the usual distortion due to the exercise of monopoly power, whose importance will depend on the specificities of $G(p)$.

In the arrangements based on PLI or ex-ante leverage, the presence of a monopolistic ex-ante financier will simply raise the cost of the equilibrium arrangement, up to the point where the incumbent is left with an expected net payoff equal to its outside option. The value of this outside option depends on whether the incumbent

\footnotetext{
${ }^{31}$ In this case the monopolistic financier could also try to screen across realizations of $p$ by offering a menu of contracts. For example, the menu could specify repayments and credit-award probabilities, making credits with a lower repayment be awarded with smaller probability. For brevity, we abstract from this possibility.
} 
can alternatively resort to ex-post financing or has no other alternative but to accommodate entry for all $p$. Of course, in the former case, the incumbent's outside option will be more valuable if the ex-post financing market is competitive than if it is also monopolized by a financier.

Across the various cases, a common pattern emerges: the structure of the credit market affects the distribution between the incumbent and its financier of the surplus from patent predation deterrence and from litigation, but the entry outcome is generally unaffected. Regarding the litigation margin, the difference emerges under ex-post financing with asymmetric information, since monopoly pricing tends to reduce the extent of cross-subsidization and, thus, the levels of litigation.

\section{$6 \quad$ Infringement defense financing}

The PLI arrangements discussed in previous sections provide what the industry calls "infringement abatement coverage." The analysis has shown how this coverage allows an incumbent firm with a patent not only to guarantee its legal defense in case of infringement by a rival firm (for which other ex-post financing alternatives might be available) but, more importantly, to reduce the risk of infringement by dissuading the rival from entering the market. However there is another form of PLI that provides "infringement defense coverage." This contract covers the legal costs of the firm sued by another for having infringed its patent. Does our analysis provide a rationale for this second form of PLI?

At first glance, the answer is no. Given the structure of the basic model, the rival firm, as a potential infringer of the incumbent's patent, would be the natural user of infringement defense coverage. Yet the rival's position as a first mover in the entry game leaves no possible commitment role for such form of PLI, which hence would be redundant - just as good as the ex-post internal financing of the rival that we have assumed so far. 
The answer turns into a yes if we look at a different, but related game. As recently put forward by Jaffe and Lerner (2004), some firms with patents sue their competitors, even in cases without much merit, in an attempt to force them to exit the market where they compete. In some instances, the defendant is a genuine innovator which did not care about patenting its own product (which might actually have been the object of protection); in other, the allegedly infringed patent protects products or processes which are not really new. In both sets of instances, we could think of the defendant as our incumbent $(i)$ and the opportunistic plaintiff as its rival $(j)$. A new game could then be devised in which, in the status quo, both firms share the market and obtain future revenues of 1 each. The rival moves first deciding whether to sue the incumbent for infringing one of its patents, in which case the incumbent must decide whether to avoid the legal confrontation (and its costs of $c$ per side) by exiting the market or to face a trial which it will win with probability $p$ - a parameter now inversely related to the strength of the rival's patent. The realization of $p$ is revealed before the rival decides whether to sue or not. The net payoffs in each of the final nodes of this game appear in Table 7 and are self-explanatory.

Table 7: The infringement defense game

\begin{tabular}{lcc}
\multirow{2}{*}{ Final node } & \multicolumn{2}{c}{ Net payoffs } \\
\cline { 2 - 3 } & Rival & Incumbent \\
\hline \hline No suit: & 1 & 1 \\
\hline Suit, exit: & $1+\pi$ & 0 \\
\hline Suit, litigation & & \\
$\quad$ - Incumbent wins (prob. $p$ ): & $1-2 c$ & 1 \\
$\quad$ - Incumbent loses (prob. $1-p$ ): & $1+\pi$ & $-2 c$ \\
\hline \hline
\end{tabular}

With similar derivations to the ones for the basic model, the equilibrium of the game in the internal financing benchmark can be easily described in reference to two critical values of the parameter $p$ : the lowest probability of winning for which the 
incumbent will stay in the market,

$$
p_{i}^{\prime} \equiv \frac{2 c}{1+2 c}
$$

and the highest probability of losing for which the rival will sue the incumbent,

$$
p_{j}^{\prime} \equiv \frac{\pi}{\pi+2 c} .
$$

The internal financing equilibrium (as well as the equilibrium with ex-post external financing) will feature predation if $p_{j}^{\prime}<p_{i}^{\prime}$ or, equivalently, if $\pi<4 c^{2}$ : for $p \in\left[p_{j}^{\prime}, p_{i}^{\prime}\right)$, the rival will sue the incumbent because it correctly anticipates that the incumbent will not want to litigate (i.e. will exit the market). It would be immediate to show that the incumbent might prevent this predatory litigation from happening by taking a properly designed PLI arrangement with infringement defense coverage. In fact, the incumbent's second-best outcome (in which it is sued and exits only for $p \in\left[0, p_{j}^{\prime}\right.$ ), and no litigation occurs) can be implemented by introducing a positive deductible, very much in line with the analysis of our basic model - so as to prevent wasteful litigation.

\section{Concluding remarks}

Intellectual property rights are the centerpiece of the system of rewards to innovators. In this paper we have studied the interplay between the prospects of infringement of intellectual property rights, the incentives of innovators to litigate in their defense, and the financing of the litigation costs. For concreteness, we have focused on the notable and empirically relevant example of patents, but the logic of our results extends trivially to any form of intellectual property protected by the law.

We have analyzed the implications of the various financing alternatives for the levels of infringement and litigation, and thus for the effective protection of the innovator. We have shown that external financing can be useful for what we have 
called patent-predation deterrence. Specifically, patent litigation insurance and several forms of ex-ante leverage may provide the innovator with a stronger commitment to litigate in defense of the patent than in the internal financing benchmark and hence lead to lower levels of infringement.

Of course, the issue of patent vulnerability due to financial weakness might resurface in the presence of imperfections such as contract enforceability and renegotiation costs that lead to the emergence of debt overhangs, moral hazard problems exacerbated by external financing or institutional impediments to small firms' access to credit markets (for example, burdens associated with bank capital regulations). Clearly, if financial weakness makes ex-post financing unaffordable (but is not severe enough to impede subscribing PLI), then PLI may become the only feasible means of patent defense and its economic role will be obvious. In this sense, our paper shows that PLI may play a role above and beyond the obvious one, a role that may be relevant for a wider spectrum of firms.

Practitioners often emphasize the strategic implications of patent protection. It is commonly argued that long-term players in the field of innovation have incentives to build a reputation of litigating any infringement. This reputation can apply to posterior infringements of the same patent as, for example, in Choi (1998), or to infringements of other patents of the same patentee, where a reinterpretation of the classical chain-store model of Kreps and Wilson (1982) (on reputation building) for patent predation deterrence is immediate. In this second case, the size of the innovator seems an important determinant of the benefit from building a reputation. Clearly, innovators with a large portfolio of patents will typically be more interested in building a reputation, than smaller firms with one or a small number of patents ${ }^{32}$ In this respect, the introduction of PLI can be interpreted as an alternative for reputation building: a simple, contractual solution for those small innovators that, from

\footnotetext{
${ }^{32}$ This can explain the evidence on the patent and litigation patterns of small firms uncovered by Lerner (1995) and Lanjouw and Schankerman (2004).
} 
a patent predation deterrence perspective, would benefit from committing to litigate all infringements, but lack the size that would give them incentives to build a reputation for doing so. Thus, introducing PLI can contribute to level the playing field for small innovators. Importantly, the commitment value of PLI is independent of the reliance of small firms on external financing since, according to the above interpretation and our previous results, it is not their financial vulnerability but the commitment capacity linked to their size what makes them weak.

The policy debate on PLI in the European Union is currently focused on the introduction of a possibly compulsory, PLI scheme. At a first approximation, our results provide no rationale for the compulsoriness of PLI. We have shown that a PLI policy with a properly chosen deductible can implement the innovator's second-best outcome: predation by deep-pocketed competitors can be prevented without the cost of excessive litigation. In principle, a competitive insurance market should be able to provide PLI policies tailored to the characteristics of each innovator (as the optimal deductible and premium depend on innovation-specific parameters), while compulsoriness might imply imposing the same policy to all patentholders. Governments should simply care about facilitating the existence of the market.

Yet possibly the reason why PLI has become a policy issue in Europe is the perception that the current development of the PLI market is insufficient. We can conjecture two causes for such underdevelopment. One might be the existence of start-up costs and the absence of the critical mass of PLI subscribers that would allow insurance companies to cover these costs. A second reason might be adverse selection, which in terms of our model would correspond to a situation where the innovator is privately informed about the strength of the patent when it approaches its potential insurer - in which case the situation would resemble that of our asymmetricinformation ex-post financing scenario. Introducing a compulsory PLI scheme is a potential solution to both market failures, but the costs of a one-size-fits-all scheme should be carefully taken into account. 


\section{Appendix}

\section{Uniqueness of the equilibria characterized in Proposition 3}

We first rule out the possibility of having other equilibria in which entry is not followed by litigation. Entry always occurs over intervals of the form $[0, x)$, so the only two situations not covered in Proposition 3 are $x<p_{j}$ and $x>p_{i}$. The first situation cannot be an equilibrium because we already know that for $p<p_{j}$ the rival strictly profits from entry even in the face of litigation. In order to sustain the second situation as an equilibrium, financiers' expectation about entry should be $p_{f}=x$ and entry decisions should be based on expecting litigation for all $p \geq x$, that is, on having $\bar{p}(R)=x$. We can prove, however, that in this case a financier could profitably deviate by offering some $R^{\prime}<R$ with $p\left(R^{\prime}\right)>p_{i}$, that is, $R^{\prime}>\hat{R} \equiv \bar{p}^{-1}\left(p_{i}\right)$. Indeed, such financier's expected net payoff would be

$$
\Pi\left(R^{\prime}, x\right)=p\left(R^{\prime}, x\right)\left(R^{\prime}-c\right)+\left[1-p\left(R^{\prime}, x\right)\right](1-2 c)>p_{i}(\hat{R}-c)+\left(1-p_{i}\right)(1-2 c)=0,
$$

where the inequality comes from the fact that $p\left(R^{\prime}, x\right)=E\left[p \mid p\left(R^{\prime}\right) \leq p<x\right]>p\left(R^{\prime}\right)$ and $R^{\prime}>\hat{R}$, while the last equality is a property of $\hat{R}$ that can be verified using (2) and (5).

Next we prove that there are no equilibria in which entry is followed by litigation. Having entry followed by litigation would require $p_{j}>\bar{p}(R)$, in which case entry would occur for $p \in\left[0, p_{j}\right)$ and litigation would occur for $p \in\left(\bar{p}(R), p_{j}\right)$, thus financiers' expectation about entry should be $p_{f}=p_{j}$, and the expected net payoff from financing the incumbent would be:

$$
\Pi\left(R, p_{j}\right)=p\left(R, p_{j}\right)(R-c)+\left[1-p\left(R, p_{j}\right)\right](1-2 c) .
$$

However, $\pi \leq 4 c^{2}$ implies $p_{j}<p_{i}$ and thus $p\left(R, p_{j}\right)=E\left[p \mid \bar{p}(R) \leq p<p_{j}\right]<p_{i}$ and also $R<\bar{p}^{-1}\left(p_{j}\right)<\bar{p}^{-1}\left(p_{i}\right) \equiv \hat{R}$. But this implies

$$
\Pi\left(R, p_{j}\right)<p_{i}(\hat{R}-c)+\left(1-p_{i}\right)(1-2 c)=0,
$$

which means that the financier incurs expected losses and so will prefer offering no financing at all. 
Proof of Proposition 3. We will show that for any $x \in\left[p_{j}, p_{i}\right)$ it is possible to construct an equilibrium in which entry occurs for $p \in[0, x)$ and is not followed by litigation. To see this, fix any $x \in\left[p_{j}, p_{i}\right)$ and consider the repayment $R^{*}=\bar{p}^{-1}(x)$. By construction, if the rival expects financiers to demand this repayment, entry will occur for $p \in[0, x)$ and will not be followed by litigation. Since litigation does not occur, financiers break even under $R^{*}$. Moreover, no financier can strictly profit by undercutting $R^{*}$. Actually, if the rival makes its entry decision based on expecting $R^{*}$ but a financier deviates and offers some $R^{\prime}<R^{*}$, then entry will be followed by litigation for all $p \in\left[\bar{p}\left(R^{\prime}\right), x\right)$ and in each of those values of $p$ the deviating financier will obtain a net payoff

$$
p\left(R^{\prime}-c\right)+(1-p)(1-2 c)<p_{i}(\hat{R}-c)+\left(1-p_{i}\right)(1-2 c)=0,
$$

where $\hat{R} \equiv \bar{p}^{-1}\left(p_{i}\right)$, and the first inequality follows from the fact that $p<x<p_{i}$ and $R^{\prime}<R^{*}<\hat{R}$, since $\bar{p}(\cdot)$ is increasing, while the last equality is a property of $\hat{R}$ that can be verified using (2) and (5). For other values of $p$, the deviating financier will not be demanded support and will thus obtain a zero net payoff, so overall he will incur expected losses.

\section{Analysis of the no-predation case}

Here we turn to the analysis of ex-post and ex-ante financing in the case with $\pi>4 c^{2}$. We will not analyze the games associated with the different possible scenarios with the same detail as in the main sections of the paper, since a good part of the logic and derivations are trivial extensions of those seen in the patent predation case $(\pi \leq$ $4 c^{2}$ ). In fact, the structure of the games played in each scenario and the net payoffs associated with the contracts signed by the incumbent and the financier coincide with those described in those sections. All differences with respect to that case come from the fact that the intervals of realizations of the patent-strength parameter $p$ for which litigation is overall valuable to the incumbent, $\left[p_{i}, 1\right]$, and for which entering in the face of litigation is valuable to the rival, $\left[0, p_{j}\right)$, overlap.

Two major implications follow. First, since the rival has deep pockets and its financial status does not change across the various scenarios, entry will always occur up to $p_{j}$. Second, since defending the incumbent's patent constitutes a positive net value investment over the interval $\left[p_{i}, p_{j}\right)$, some litigation and no patent predation 
will occur in equilibrium. Actually, the incumbent's second-best outcome in this no-predation case is precisely having entry for $p \in\left[0, p_{j}\right)$ and litigation for $p \in$ $\left[p_{i}, p_{j}\right)$. Thus, Proposition 1 directly implies that the second-best is implemented in the internal financing benchmark. But then, by the same logic as in the patent predation case, we have that, under perfect information, ex-post financing implements the incumbent's second-best outcome. This also means that, with perfect information in the ex-post financing stage, ex-ante arrangements such as PLI or ex-ante leverage add nothing to the defense of the patent.

The only scenario that requires further analysis is that with asymmetric information at the ex-post financing stage. As in subsection 3.1.2, the equilibrium involves a balance of expectations about patent-defense by the rival and about entry by the financier. The (lowest) repayment demanded by financiers after observing entry, $R$, determines a critical value of the patent-strength parameter, $\bar{p}(R)$, given by (5), above which the incumbent will defend its patent. From what we already know, if $\bar{p}(R)<p_{j}$, then the rival will enter for all $p \in\left[0, p_{j}\right)$ and the only consistent expectation that financiers can hold is that entry will occur up to $p_{f}=p_{j}$. Clearly, in this situation, the net payoff of the financier who demands the repayment $R$ would be

$$
\Pi\left(R, p_{j}\right)=p^{e}\left(R, p_{j}\right)(R-c)+\left[1-p^{e}\left(R, p_{j}\right)\right](1-2 c),
$$

where $p^{e}\left(R, p_{j}\right)=E\left[p \mid \bar{p}(R) \leq p<p_{j}\right]$. Now, as we show in the proof of the following proposition, with $p_{i}<p_{j}$, the equation $\Pi\left(R^{*}, p_{j}\right)=0$ has a unique, meaningful solution $R^{*}<1+\pi+c$, with $p\left(R^{*}\right)<p_{i}$, which identifies the unique equilibrium of the game.

Proposition 6 With $\pi>4 c^{2}$, ex-post financing under asymmetric information induces entry for $p \in\left[0, p_{j}\right)$ and litigation for $p \in\left[p^{*}, p_{j}\right)$, where $p^{*}<p_{i}$.

Proof. We know that the break-even $R$ for $p^{e}\left(R, p_{j}\right)=p_{i}$ would be $\hat{R}=\bar{p}^{-1}\left(p_{i}\right)$, but with such a repayment the incumbent would litigate over the whole interval $\left[p_{i}, p_{j}\right)$, so we would have $p^{e}\left(\hat{R}, p_{j}\right)>p_{i}$ and, then, $\Pi\left(\hat{R}, p_{j}\right)>0$. Starting from $R=\hat{R}, p^{e}\left(R, p_{j}\right)$ is decreasing in $R$ and, thus, $\Pi\left(R, p_{j}\right)$ is strictly decreasing in $R$. Moreover, by (1), $\Pi\left(R, p_{j}\right)$ is negative when $R$ is sufficiently close to zero. Therefore, the equation $\Pi\left(R^{*}, p_{j}\right)=0$ must have a unique solution with $0<R^{*}<\hat{R}$ and thus $\bar{p}\left(R^{*}\right)<\bar{p}(\hat{R})=p_{i}$. To show that the unique break-even repayment $R^{*}$ identifies the 
unique equilibrium of the game, notice first that no financier can profitably deviate from it: offering a $R<R^{*}$ would yield strictly negative expected profits (by inducing the incumbent to litigate for some $p<\bar{p}\left(R^{*}\right)$ ), while a $R>R^{*}$ would not be demanded for any $p$. Finally, notice that no equilibrium can be supported by a non-break-even repayment $R^{\prime}$, since it would imply that either a profitable undercutting exists (if $R^{\prime}$ yields positive profits) or financiers would prefer to offer no financing at all (if $R^{\prime}$ yields losses).

Thus, the presence of asymmetric information does not change the entry margin $p_{j}$ but induces excessive litigation: the wasteful litigation that occurs over the interval $\left[p^{*}, p_{i}\right)$ is cross-subsidized by the overall valuable litigation that occurs over the interval $\left(p_{i}, p_{j}\right)$. Hence, in the no-predation case, asymmetric information is ex-ante detrimental to the incumbent, which is in sharp contrast with the patent predation case, where, if anything, asymmetric information could facilitate some patent predation deterrence (Proposition 3).

The remaining question is whether an ex-ante arrangement might serve to correct the inefficiencies of ex-post financing with asymmetric information. The answer is a qualified yes. Obviously, the incumbent might contract with a third party such as the financier so as to establish a system of pecuniary penalties and rewards that (i) guarantees the availability of litigation funding whenever convenient, and (ii) limits the incumbent's incentives to litigate to the second-best range $\left[p_{i}, 1\right]$. However, such a stick-and-carrot mechanism would have no natural interpretation either as a PLI policy or as ex-ante leverage. Essentially, it would imply that the incumbent pays out to the financier a large part of its revenue in case of succeeding in the litigation ("the stick") and receives a positive payoff from the financier in case of not litigating ("the carrot"). Moreover, ex-post, for some realizations of $p$, the incumbent would have incentives to bypass the ex-ante financier and to finance its litigation secretly with another financier. This means that the ex-ante arrangement imposes obligations (instead of giving rights) to the incumbent as for the financing of litigation, and that its implementation would require explicit contingency on the litigation outcome. 


\section{References}

Aoki, R., and J. L. Hu (1999) "Licensing vs. Litigation: The Effect of the Legal System on Incentives to Innovate," Journal of Economics and Management Strategy, 8: $133-160$.

Bebchuk, L., and H. Chang (1996) "An Analysis of Fee-Shifting Based on the Margin of Victory: On Frivolous Suits, Meritorious Suits, and the Role of Rule 11," Journal of Legal Studies, 25: 371-403.

Betterley, R. (2004) "Intellectual Property Insurance Market Survey 2004: Fewer Carriers and Some Interesting Alternatives," Report from Betterley Risk Consultants, Inc., April.

Bolton, P., and D. Scharfstein (1990) "A Theory of Predation Based on Agency Problems in Financial Contracting," American Economic Review, 80: 93-106.

Brander, J. A., and T. R. Lewis (1986) "Oligopoly and Financial Structure: The Limited Liability Effect," American Economic Review, 76: 956-970.

Choi, J. P. (1998) "Patent Litigation as an Information-Transmission Mechanism," American Economic Review, 88: 1249-1263.

CJA Consultants Ltd. (2003) "Patent Litigation Insurance: A Study for the European Commission on Possible Insurance Schemes against Patent Litigation Risks," available at http://europa.eu.int/comm/internal_market/en/indprop/patent/.

Crampes, C., and C. Langinier (2002) "Litigation and Settlement in Patent Infringement Cases," Rand Journal of Economics, 33: 258-274.

Jaffe, A. B., and J. Lerner (2004) Innovation and Its Discontents: How Our Broken Patent System is Endangering Innovation and Progress, and What to Do About It, Princeton University Press.

Kreps, D. M., and R. B. Wilson (1982) "Reputation and Imperfect Information," Journal of Economic Theory, 27: 253-279.

Lanjouw, J. O., and M. Schankerman (2004) "Protecting Intellectual Property Rights: Are Small Firms Handicapped?," Journal of Law and Economics, 47: 19-44. 
Lerner J. (1995) "Patenting in the Shadow of Competitors," Journal of Law and Economics, 38: 463-488.

Llobet, G. (2003) "Patent Litigation when Innovation Is Cumulative," International Journal of Industrial Organization, 21: 1135-1358.

Maksimovic, V. (1986) "Optimal Capital Structure in Oligopolies," Ph D dissertation, Harvard University.

Maurer, S. M., and S. Scotchmer (2004) "Profit Neutrality in Licensing: The Boundary between Antitrust Law and Patent Law," NBER Working Paper No. 10546.

Meurer, M. (1989) "The Settlement of Patent Litigation," The RAND Journal of Economics, 20: 77-91.

Myers, S. (1977), "Determinants of Corporate Borrowing," Journal of Financial Economics, 5: 147-175.

Perotti, E., and K. Spier (1993) "Capital Structure as a Bargaining Tool," American Economic Review, 83: 1131-1141. 